\title{
Evaluating the effectiveness of emergency relief of the Central Emergency Response Fund after natural disasters
}

\author{
Sacha den Nijs ${ }^{1}$
}

\begin{abstract}
Natural disasters are increasingly common and emergency relief is often provided to help the affected countries recover. The United Nations started the Central Emergency Response Fund (CERF) in 2005 that allows for fast allocation of money to providers of humanitarian aid. This thesis evaluates this fund with respect to natural disasters, since its effectiveness can have implications for future emergency relief allocations. The following question is answered: Do the grants provided by the Central Emergency Response Fund decrease the output growth volatility caused by natural disasters? A panel database is constructed and dynamic panel models are estimated by applying the Generalised Method of Moments. Results show that when CERF funding is provided after a natural disaster, the expected effect on output growth volatility of the natural disaster is neutralised and close to zero. This implies that CERF funding is effective, however, reports on the functioning of CERF report possible improvements concerning the allocation. Furthermore, alternative estimation methods might provide consistent results.
\end{abstract}

\section{Introduction}

Recently, reports about global warming have been predicting an increase in natural disasters, such as earthquakes, droughts and tsunamis. Such natural disasters can have dire consequences for the economies of the countries affected by it. The paper by Raddatz (2009), shows an increase in the incidence of such disasters of $30 \%$ in the last decades. Furthermore, a significant effect on the GDP per capita of affected countries has been established. Many different organisations provide international aid after such catastrophes. The United Nations (UN) started an initiative to better structure the provision of emergency aid and offer faster funding to humanitarian organisations. In 2005, the Central Emergency Response Fund (CERF) was established, which is funded by voluntary contributions both from governmental and non-governmental organisations (World Health Organization, 2010). Its objective is to focus on life-saving activities by giving out grants. Special Rapid Response grants are given in such sudden crises as natural disasters and can be provided within 48 hours. An example of this is the CERFfunded response in 2015-2016, when El Niño caused flooding in several continents, leading to a humanitarian crisis (CERF, 2016b). Furthermore, Rapid Response grants are also provided in cases of armed conflicts.

As many countries provide different kinds of emergency aid, it is useful to analyse the effectiveness of the Rapid Response grants provided by CERF. Natural disasters have an effect on the growth rate of countries (Fomby, Ikeda et al. 2013) and often the focus for emergency relief is of a humanitarian nature, but a stabilising effect for the economy could be the result. Evaluating CERF's Rapid Response grants can help for further comparison to other emergency aid programmes. Therefore, the research question is the following: Do the grants provided by the Central Emergency Response Fund

\footnotetext{
${ }^{1}$ Sacha den Nijs is an undergraduate student in Economics \& Business Economics, specialising in international economics. At the moment she is an exchange student at Stellenbosch University, South Africa. Contact: sachadennijs96@gmail.com
} 
decrease the output growth volatility caused by natural disasters? The question is split up in three elements. First, it is important to know what happens to an economy when a natural disaster occurs. Second, the CERF allocation of Rapid Response grants is relevant and its economic impact. Third, the combination of a natural disaster with CERF funding on the output growth volatility, which is the main focus of the thesis. This thesis first provides a theoretical framework, where concepts are defined and previous research is discussed. Next, the methodology discusses the models, data and estimation method used. This is followed by the data analysis and estimation output, and in the discussion results are interpreted. Finally, the conclusion summarises the results, answers the research question and mentions the limitations of this research.

\section{Theoretical framework}

In order to evaluate the effectiveness of CERF, several concepts should be defined. Furthermore, previous research suggests expected outcomes. While much research has been done on natural disasters, humanitarian relief and the allocation of emergency relief, specific economic evaluations of funding systems are rare. First, the effect of natural disasters on the economy is discussed. Next, attention is given to the effect of emergency relief, followed by a discussion on CERF itself.

\subsection{Natural disasters and the economy}

In the paper of Spiegel, Le et al. (2007), a natural disaster is defined as some form of natural hazard which affects the population or an area, and can result in severe damage and increases morbidity and mortality. Often, the community needs international aid to be able to cope with such a disaster. The main difference with other disasters is that it is caused by a natural phenomenon and not by humans. Figure 1 shows the occurrence of several kinds of disasters per region, as determined by the United Nations. Mainly Asia, Latin America and the Caribbean suffer from natural disasters.

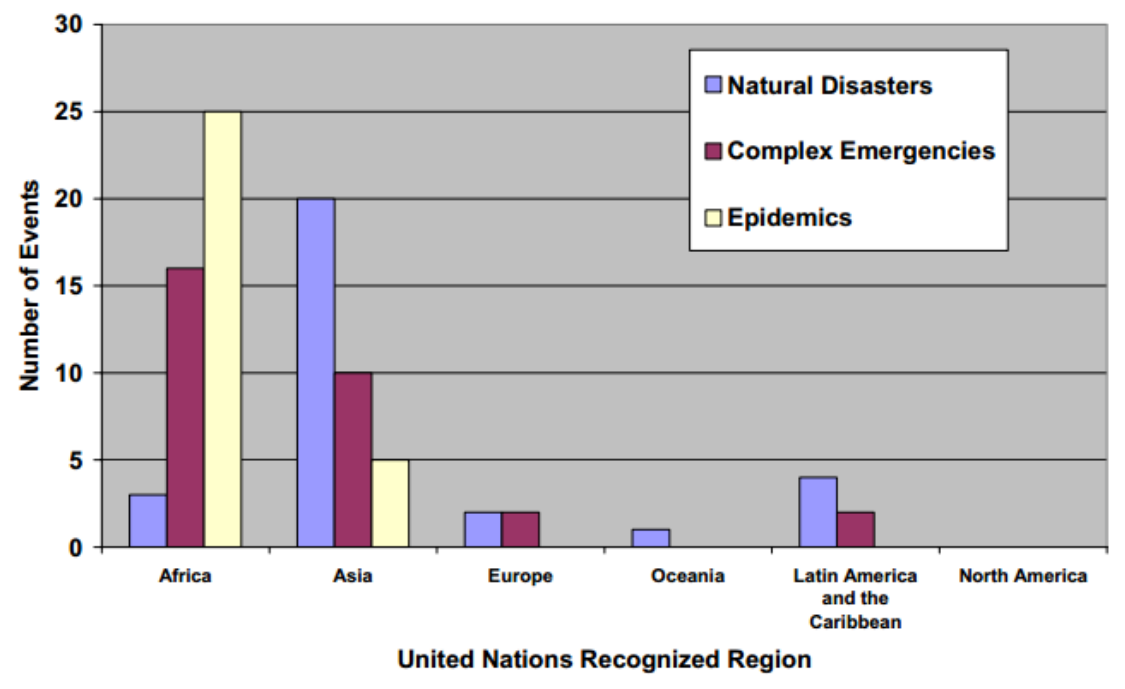

Figure 1. The occurrence of disasters per United nations recognized region - source: Spiegel, P. B., et al. (2007). "Occurrence and overlap of natural disasters, complex emergencies and epidemics during the past decade (1995-2004)." Conflict and Health 1: 2-2.

92 \begin{tabular}{l|l} 
Marble \\
Research \\
Papers
\end{tabular} 
These natural disasters affect the economy of a country. For example, Kuropka and Jankowiak (2016) analyse the effects of natural disasters in ASEAN countries. They mention the high number of deaths, the destruction of infrastructure, and the integration of production networks, which requires a stable environment. In case of a natural disaster, such a production network can incur high costs, as was for example the case in Thailand after a flood in 2011.

Some theoretical channels through which a natural disaster can affect the economy are described by Samphantharak (2014). First, there is a loss of physical capital due to the destruction caused by the disaster. This can lead to a decrease in output and foregone income. Second, due to the increased morbidity and mortality, there is a decrease of human capital. Education and health institutions are affected. Furthermore, following Schumpeter's idea of 'creative destruction' and the convergence debate, theory suggest that there are also positive effects of natural disasters, as the economy has more opportunities to grow again. Fomby, Ikeda et al. (2013) apply an empirical approach, where they focus on the growth aftermath of natural disasters. By using panel data from 84 different countries and distinguishing between different types of natural disasters, they find heterogeneous effects. The effects of natural disasters turn out to be stronger on developing countries than on developed countries. Also, not every natural disaster has the same effects. Some moderate natural disasters can even have benefits. However, when a natural disaster is severe, there are never positive effects. Porfiriev (2016) complements this result, stating that the effect of a natural disaster on the economy depends on the following factors: the size of the economy and the type of the natural disaster. Furthermore, he also states that recent research finds negative relationships between the occurrence of a natural disaster and GDP growth. Here, the effect is also greater on developing countries.

\subsection{Emergency relief and the economy}

The theory concerning the effectiveness of funding for aid is large and extensive. For example, Cohen and Werker (2008) create a model for the amount of aid a government should provide after a natural disaster. They extend this model for the chance of theft, problems concerning moral hazard and the discussion regarding investing in prevention. However, their approach is purely theoretical. Similarly, many other models are extended to include international aid, such as the Solow model. Furthermore, models have been developed which try to explain the consequences of a natural disaster. For example, Carter, Little et al. (2007) set up a model that describes asset shocks due to a natural disaster, which leads to a poverty trap for households which are below a certain threshold level. Also, much attention is given to the allocation problems that occur when providing international (monetary) aid.

Strömberg (2007) discusses the relation between natural disasters, economic development and disaster relief. As the effects of natural disasters are found to be more severe in low-income countries, international relief can have great influence. Using the Development Assistance Committee (DAC) data and data on natural disasters, he found that Africa, Asia and Europe are the main recipients of disaster relief. Furthermore, he evaluates the allocation of relief provided by the Office of Foreign Disaster Assistance (OFDA) from the United States. Its functioning is comparable to the CERF organisation, however, on a bilateral level. The regression results show that an increase in the deaths due to the disaster leads to an increase in the chance of receiving funding. Also, media coverage increases this probability. Furthermore, the distance from the donor country to the recipient is also an important factor in receiving funds. An empirical research which does look at the effectiveness of aid is done by Ebeke and Combes (2013). The focus lies on the effect of remittances after natural disasters on output growth volatility. Natural disasters often lead to an increase in remittances; however, this does not need to be

Evaluating the effectiveness of Emergency relief of the Central Emergency Response Fund after natural disasters 
stabilising for the economy. For example, these remittances might generate inflation and real exchange rate depreciation. Similar to Fomby, Ikeda et al. (2013), they find a positive relation between natural disasters and output growth volatility. According to their statistical output, remittances have a stabilising effect, which is maximised when the ratio of remittances to Gross Domestic Product (GDP) is between $8 \%-17 \%$.

\subsection{The CERF organisation and Rapid Response grants}

The Central Emergency Response Fund (CERF) was established in 2005 by the UN General Assembly, and replaced the Central Emergency Revolving Fund. This meant that the fund is now also able to give out grants, instead of only providing loans. This grant element is split up into two categories: The Rapid Response window and the Underfunded Emergencies window (Channel Research, 2011). The first window focuses on providing funds for UN agencies as fast as possible, so humanitarian operations can start saving lives after a crisis. This is mainly important since these UN agencies otherwise have to gather funds themselves, before being able to start providing this aid. Such a Rapid Response fund can thus speed up the process.

Figure 2 shows the functioning of the CERF fund. The UN agencies identify the need for the funds and send a request to CERF. Here, following certain 'CERF Life-saving Criteria' the situation is analysed and a decision is made. The fund consists of donor contributions, which are done before the need for a specific fund arises. The CERF secretariat (2015) 10-year report shows the main donors, which are UN member states such as the United Kingdom, Sweden, and Norway. However, also individuals and nongovernmental organisations are able to donate to the fund. Reports and information provided by the United Nations seems positive about the effectiveness of CERF. However, other sources seem more critical. The 5-year evaluation done by Channel Research (2011) shows several weaknesses of the fund. For example, funding is not always allocated fast enough, especially when nongovernmental, independent aid agencies want to apply for the fund. No formal economic analysis has been performed. Therefore, applying the existing literature on international aid and its effectiveness on the CERF organisation can bring new insights.

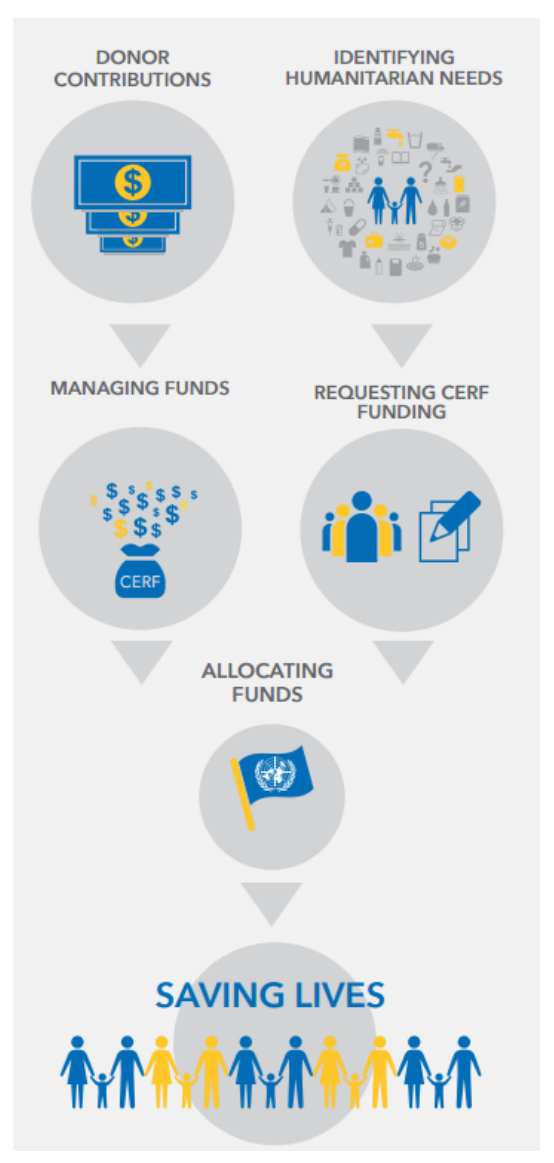

Figure 2. How does CERF work? Source: CERF secretariat (2015). "10 Years of Saving Lives Together: The World Helping the World." From http://reliefweb.int/sites/reliefweb.int/files/ resources/CERF\%2010\%20Report.pdf.

\section{4 $\begin{aligned} & \text { Marble } \\ & \text { Research } \\ & \text { Papers }\end{aligned}$}




\section{Methodology}

To determine the effectiveness of the CERF funding, a similar approach is applied as in the research by Ebeke and Combes (2013). By collecting data from several sources and testing models, one can see whether the output growth volatility has decreased or increased due to a natural disaster in combination with CERF funding. First, the three models are specified. Second, the data used is discussed, and finally, the estimation method is explained.

\section{$3.1 \quad$ Models}

Model 1 establishes the relationship between the occurrence of a natural disaster and the size in terms of deaths, and the output growth volatility. The model is also extended to include armed conflicts, as these are also part of the CERF funding.

$\sigma_{i, t}=\beta_{0}+\beta_{1} \sigma_{i, t-1}+\beta_{2}$ deaths natural disaster ${ }_{i, t}+u_{i}+\varepsilon_{i, t}$

Where $\sigma$ is the output volatility and the second term is a lag of the output volatility. Furthermore, $u$ represents the country fixed effects. The occurrence and impact of a natural disaster is here measured as the deaths due to the natural disasters happening in a certain year as a percentage of the population in that year. The expected outcome here is a positive effect, similar to other papers. Thus, the null hypothesis tested here is that $\beta_{2}>0$. Also, the model is extended to control for severity of the natural disasters, where one would expect a more severe disaster to have greater impact on the output growth volatility.

Model 2 specifically looks at the effect of the CERF funding on the output growth volatility, without taking into account disasters and their size.

$\sigma_{i, t}=\gamma_{0}+\gamma_{1} \sigma_{i, t-1}+\gamma_{2}$ CERFfundratio $_{i, t}+u_{i}+\varepsilon_{i, t}$

The CERF funding is measured as the percentage of funding-to-GDP of a country. Here, the expected outcome is a negative effect of the relief on the output volatility, thus the following hypothesis is tested: $\gamma_{2}<0$.

Model 3 combines the two previously tested models. By including an interaction variable between natural disasters and a CERF fund dummy, the interactions between the variables can be disentangled and analysed. The model is also extended to include the deaths due to armed conflicts and interaction variables, to control for these funds from CERF.

$\sigma_{i, t}=\theta_{0}+\theta_{1} \sigma_{i, t-1}+\theta_{2}$ natural disaster $_{i, t}+\theta_{3}$ CERFfunddummy $_{i, t}+\theta_{4}$ natural disaster $_{i, t} \cdot$ CERFfunddummy $_{i, t}+u_{i}+$ $\varepsilon_{i, t}$

From model 3 the expected result is the following: a natural disaster will increase output volatility, thus $\theta_{2}>0$, and an increase in relief, when a natural disaster happens, decreases this volatility: $\theta_{4}<0$. It is not clear what the effect is of emergency relief when there is no natural disaster, so it is not possible to do a prediction on the sign of $\theta_{3}$. 


\subsection{Data}

To be able to test these models, a panel database is constructed. First, the data from CERF are used. The allocations around the world per country for the years 2006-2016 can be found on the website (CERF, 2016a). This last year is excluded due to incompleteness at the time of writing. CERF has allocated funds to 94 countries. Second, data from the World Bank, the World Development Indicators, are added to the dataset (World Bank, 2016). Data on GDP per capita and the population of the country are added. Several countries are dropped from the database due to data limitations: Palestinian territory, Cuba, Eritrea, Iran, Korea, Libya, Mauritania, Somalia, South Sudan and the Syrian Arab Republic. This leaves 84 countries in the database. Third, the data on natural disasters are collected from the Emergency Events Database (EM-DAT) (Below et al., 2016). In one country (Jordan), no natural disaster occurred and therefore it is eliminated from the dataset. For the extended models, data are obtained on the armed conflicts in a certain country from the UCDP Georeferenced Event Dataset (GED) (Melander and Sundberg, 2013). This dataset contains all armed conflicts and the corresponding deaths. Aggregating those per country per year allows for using them in the panel dataset that is created. Finally, a panel data set is obtained which contains data on 83 countries over the time period 2006-2015.

\subsection{Estimation method}

For the estimation of the models, the Generalised Method of Moments (GMM) is used. As the models are dynamic panel models, since a lag of the dependent variable is included, a suitable method should be chosen. For panel data, often Ordinary Least Squares (OLS) with fixed effects is used, or the Least Squares Dummy Variable (LSDV) method. However, several papers on econometric models mention problems that can occur when using a panel dataset with only a few years (small $\mathrm{T}$ ) and many crosssectional units. As CERF only exists for 10 years, this is relevant for this research, and a more advanced econometric method has to be applied here.

Baltagi (2008) explains the problems that occur when including a lag of the dependent variable in the model. One of the regressors, namely the lag of the dependent variable, is correlated with the error term. In this case, the lag of output growth volatility is included in the structural equation. Due to this lag, the assumption MLR.4, the zero conditional mean assumption as mentioned by Wooldridge (2013), is violated. As this assumption is one of the requirements for OLS to be unbiased, the method is biased. Assumption MLR.4', a weaker version of MLR.4, also does not hold, and therefore the method does not provide asymptotically consistent estimators. The fixed effects method does not provide a solution to this problem and is thus also biased and inconsistent. The resulting bias is often called the Nickell bias and it turns to zero as T goes to infinity. Many econometricians have suggested alternative methods to be able to estimate consistent dynamic panel estimators.

The Generalised Method of Moments (GMM), introduced by Hansen (1982), offers a solution to this problem by adding instrumental variables and is able to provide consistent estimators of the parameters of interest (Hall, 2005). Instrumental variables can help deal with endogeneity problems. By including the lags of the regressors, the correlation with the error term is eliminated. There are two requirements for a valid instrument: first, the instrument should be correlated with the regressor, and second, the instruments should not be correlated with the error term (Wooldridge 2013). Figure 3 shows a graphical representation of the use of a lag of an independent variable as an instrument. In the GMM method, this concept is used and many instruments are included to get consistent estimators.

Marble

96 Research Papers 


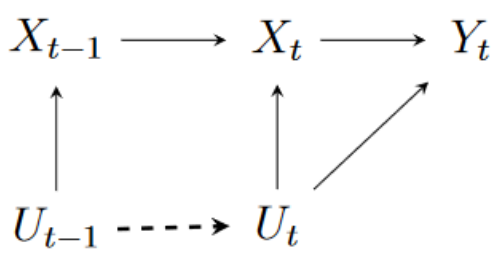

Figure 3. Including a lag of the regressor as an instrument. Source: Bellemare, Marc F. and Masaki, Takaaki and Pepinsky, Thomas B., Lagged Explanatory Variables and the Estimation of Causal Effects (February 23, 2015). From: http://dx.doi.org/10.2139/ssrn.2568724

There are different types of GMM estimation methods: difference GMM and system GMM. Here, difference GMM is used, where the data first is first-differenced to control for fixed effects. This method has been proposed by Arellano and Bond (1991) and is therefore called the Arellano-Bond GMM estimator. In this GMM estimation, lags of the dependent variables are included as instruments. A twostep estimator is used, as this estimates a large-sample robust variance-covariance matrix (Mileva, 2007). Also, the matrix is robust to panel-specific autocorrelation and heteroskedasticity. Eviews 9 provides tools to estimate the Arellano-Bond estimator, and provides relevant test statistics as well.

\section{Data Analysis}

The GMM method needs some special care when interpreting the estimation outputs. In the tables that are presented here, the P-value of the Hansen test is reported. This is based on the J-statistic, and tells something about possible overidentification in the model. It tests the null hypothesis that the instruments are uncorrelated with the error term. When the P-value is low, the model therefore is not very good, as the GMM method does not seem to provide a solution to the problem of the dynamic panel model (Mileva, 2007).

The assumption of GMM implies that the instrument is uncorrelated with the error term. Thus, in this case, the second lag of the output growth volatility should not be correlated with the error term for year $\mathrm{t}$. This can be tested by performing a test for autocorrelation, the Arellano-Bond test for zero autocorrelation (Hujer, Zeiss et al. 2005). The relevant null hypothesis here is no autocorrelation. The results of these test, for both $\operatorname{AR}(1)$ and $\operatorname{AR}(2)$ autocorrelation, are also reported below the estimation results. The models are estimated in turn, each with some additional specifications or additions to test for robustness of the results. Table 1 shows the descriptive statistics for the dataset used.

Table 1 Descriptive statistics

\begin{tabular}{cccccc}
\hline Variable & Obs & Mean & Std. Dev. & Min & Max \\
\hline $\begin{array}{c}\text { GDP per capita growth } \\
\text { volatilitv }\end{array}$ & 664 & 4.487883 & 0.061961 & 4.321330 & 4.513742 \\
Deaths natural disaster (\%) & 550 & 0.005869 & 0.098662 & $2.84^{\mathrm{E}}-06$ & 2.295578 \\
Deaths armed conflict (\%) & 337 & 0.004086 & 0.011829 & $3.65^{\mathrm{E}}-07$ & 0.130430 \\
CERF fund ratio (\%) & 405 & 0.090789 & 0.164273 & $2.37^{\mathrm{E}}-06$ & 1.840113 \\
Log(CERF fund ratio(\%)) & 405 & -3.674035 & 1.938480 & -12.95392 & 0.609827 \\
Intensity natural disaster & 830 & 0.006906 & 0.018727 & 0 & 0.213152 \\
\hline
\end{tabular}




\subsection{Model 1}

The results for the estimation of the first model can be found in table 2. The simple model only includes the deaths due to natural disasters, while the extended model also includes the deaths due to armed conflicts. Adding lags improves the model and intuitively makes sense, as a natural disaster might affect the output growth volatility in the year after it has occurred as well. The first two columns simply test the relationship between the occurrence of a natural disaster and the output growth volatility. Both the simple and the extended model estimation show a negative coefficient for deaths due to natural disasters happening in the same year. In the simple model, this is also the case for the lag. In the extended model, an increase in deaths due to a natural disaster last year is expected to have a positive effect on the output growth volatility this year. Also, armed conflicts are expected to increase the output growth volatility, however, in the same year already.

Table 2 Model 1 - Natural disasters and output growth volatility

\begin{tabular}{|c|c|c|c|c|}
\hline Model & 1 - Simple & 1 - Extended & $\begin{array}{l}1 \text { - Simple - } \\
\text { Severity }\end{array}$ & $\begin{array}{c}3 \text { - Extended - } \\
\text { Severity }\end{array}$ \\
\hline Deaths natural disaster (\%) & $\begin{array}{c}-0.003942 \\
(0.001427)^{* * *}\end{array}$ & $\begin{array}{c}-0.000696 \\
(0.014603)\end{array}$ & $\begin{array}{c}-0.021706 \\
(0.010585)^{* *}\end{array}$ & $\begin{array}{l}-0.012353 \\
(0.055805)\end{array}$ \\
\hline $\begin{array}{l}\text { Deaths natural disaster }(\%)(\mathrm{t} \\
-1)\end{array}$ & $\begin{array}{c}-0.000383 \\
(0.000150)^{* *}\end{array}$ & $\begin{array}{c}0.126824 \\
(0.028043)^{* * *}\end{array}$ & $\begin{array}{l}-0.000530 \\
(0.000547)\end{array}$ & $\begin{array}{l}-0.009357 \\
(0.020479)\end{array}$ \\
\hline $\begin{array}{l}\text { Deaths natural disaster }(\%) * \\
\text { Dummy severe intensity }\end{array}$ & & & $\begin{array}{c}0.019980 \\
(0.010772)^{*}\end{array}$ & $\begin{array}{l}-0.026872 \\
(0.051671)\end{array}$ \\
\hline $\begin{array}{l}\text { Deaths natural disaster }(\%)(t \\
-1)^{*} \text { Dummy severe intensity }\end{array}$ & & & $\begin{array}{c}0.019101 \\
(0.016290)\end{array}$ & $\begin{array}{c}0.013025 \\
(0.018425)\end{array}$ \\
\hline Deaths armed conflict (\%) & & $\begin{array}{c}0.011623 \\
(0.003560) * * *\end{array}$ & & $\begin{array}{c}0.005895 \\
(0.004541)\end{array}$ \\
\hline $\begin{array}{c}\text { Deaths armed conflict }(\%)(t- \\
1)\end{array}$ & & $\begin{array}{l}-0.000733 \\
(0.001422)\end{array}$ & & \\
\hline Output growth volatility $(t-1)$ & $\begin{array}{c}0.082382 \\
(0.000283)^{* * *}\end{array}$ & $\begin{array}{c}0.089280 \\
(0.001417)^{* * *}\end{array}$ & $\begin{array}{c}0.082717 \\
(0.000381)^{* * *}\end{array}$ & $\begin{array}{c}0.080586 \\
(0.003949)^{* * *}\end{array}$ \\
\hline Cross-Sections & 59 & 27 & 59 & 36 \\
\hline Periods & 6 & 6 & 6 & 6 \\
\hline Hansen test P-value & 0.000594 & 0.041544 & 0.511692 & 0.140974 \\
\hline Number of instruments & 12 & 12 & 12 & 12 \\
\hline $\begin{array}{l}\text { Arellano-Bond test } \\
\qquad A R(1) \\
A R(2)\end{array}$ & $\begin{array}{l}0.3117 \\
0.1868\end{array}$ & $\begin{array}{l}0.8006 \\
0.6444\end{array}$ & $\begin{array}{l}\text { NA } \\
\text { NA }\end{array}$ & $\begin{array}{l}0.4396 \\
0.8698\end{array}$ \\
\hline
\end{tabular}

Robust-White period weights standard errors are in parentheses. Regressions are at country level and time dimension. The dependent variable is the standard deviation of GDP per capita growth. Deaths are calculated as percentage of the population. The Arellano-Bond two-step estimation method is used, GMM weighting matrix White period. * significant at 10 percent; ** significant at 5 percent; $* * *$ significant at 1 percent.

One should be cautious when interpreting the simple model in column (1), since the P-value for the Hansen test is low and the null hypothesis of uncorrelated instruments with the error term can be rejected at $1 \%$. The extended model can reject this null hypothesis at $5 \%$, and is therefore also not very

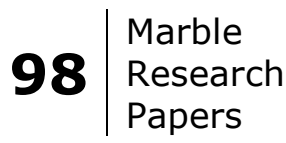


valuable. However, there are no problems with the autocorrelation, as the null hypothesis of no autocorrelation cannot be rejected.

A problem with the previous regression output might be that all disasters are included. Some are minor, and their effect on the output volatility might be incredibly small or non-existent, as appeared in other literature. Therefore, making a distinction between the severity of the disasters can be value-adding. In column (3) and (4) of table 1, a dummy variable is added which allows for different effects of severe natural disasters and non-severe natural disasters. The intensity measure follows the approach of other research, such as Fomby, Ikeda et al. (2013). The intensity is calculated as follows:

dummy severe intensity $y_{i, t}=1$, if $\frac{\text { death }_{i, t}+0.3 * \text { total affected }_{i, t}}{\text { population }_{i, t}}>0.01$, and 0 otherwise.

The P-values for the Hansen test are now higher, which suggests a better model. The coefficients that indicate the slope of the non-severe natural disasters are negative, and natural disasters this year seem to impact output growth volatility more than those that occurred last year. To determine the coefficient of the slope for severe disasters, one should add up the two separate coefficients. For the simple model, this results in a coefficient of almost zero for natural disasters in this year $(-0.021706-0.019980)$. Also, these coefficients are significant at a $5 \%$ and $10 \%$ level. The other coefficients are not significant, and the corresponding slope coefficients are quite different in both the simple and the extended model.

\subsection{Model 2}

The next model investigates the relationship between CERF funding and the output growth volatility. Table 3 shows both the results that are obtained by using GMM, but also a different specification that is obtained by applying fixed effects.

Table 3 Model 2 - CERF Funds and output growth volatility

\begin{tabular}{ccc}
\hline Model & 2 & 2 \\
\hline Method & Fixed effects & GMM \\
\hline CERF fund ratio (\%) & 0.000364 & \\
CERF fund ratio $(\%)^{2}$ & $(0.000166)^{* *}$ & \\
Log(CERF fund ratio (\%)) & $(9.78 \mathrm{E}-05)^{*}$ & $1.45 \mathrm{E}-05$ \\
Output growth volatility $(\mathrm{t}-1)$ & & $(2.19 \mathrm{E}-06)^{* * *}$ \\
Intercept & 0.291949 & 0.081318 \\
& $(0.003950)^{* * *}$ & $(0.000851)^{* * *}$ \\
Cross-Sections & 3.202767 & \\
Periods & $(0.017697)^{* * *}$ & 6 \\
Hansen test P-value & 78 & 0.000697 \\
Number of instruments & 7 & 16 \\
Arellano-Bond test & - & \\
AR(1) & - & 0.0213 \\
AR(2) & - & 0.5750 \\
\hline
\end{tabular}

Robust-White period weights standard errors are in parentheses. Regressions are at country level and time dimension. The dependent variable is the standard deviation of GDP per capita growth. CERF fund ratio is calculated as a percentage of GDP. The Arellano-Bond two-step estimation method is used, GMM weighting matrix White period. * significant at 10 percent; ** significant at 5 percent; *** significant at 1 percent. 
This is due to the low P-value of the Hansen test, which does not provide much proof for the GMM method in this case. Even though fixed effects might not be consistent, a comparison might be useful. With GMM, the best specification is one where the log is taken of the CERF fund to GDP ratio. For the fixed effects method, the most suitable specification includes a squared term of the CERF fund to GDP ratio.

The GMM estimation indicates a small coefficient close to zero for the logarithmic term, which is significant at a $1 \%$ level. For the fixed effects method, the linear term has a positive coefficient, significant at $5 \%$. The quadratic term, however, has a negative sign and is significant at a $10 \%$. The negative sign for the quadratic term implies a parabolic shape with a maximum.

From the data analysis followed that there are two possible specifications that suit the data. One is a logarithmic form, and the other is one of linear-quadratic form, which implies interesting results. Figure 4 shows the specification preferred by the GMM method. Thus, the expected effect of the CERF funding is upward sloping, meaning that as the CERF fund ratio increases, the output growth volatility increases as well. When CERF funding is equal to one, the logarithm equals zero. From this simplified picture, one could argue that CERF funding is thus only effective up to $1 \%$ of GDP. However, if an intercept is included, this threshold might change. Due to the positive slope, an increase in the funding will lead to a less strong effect on the output growth volatility.

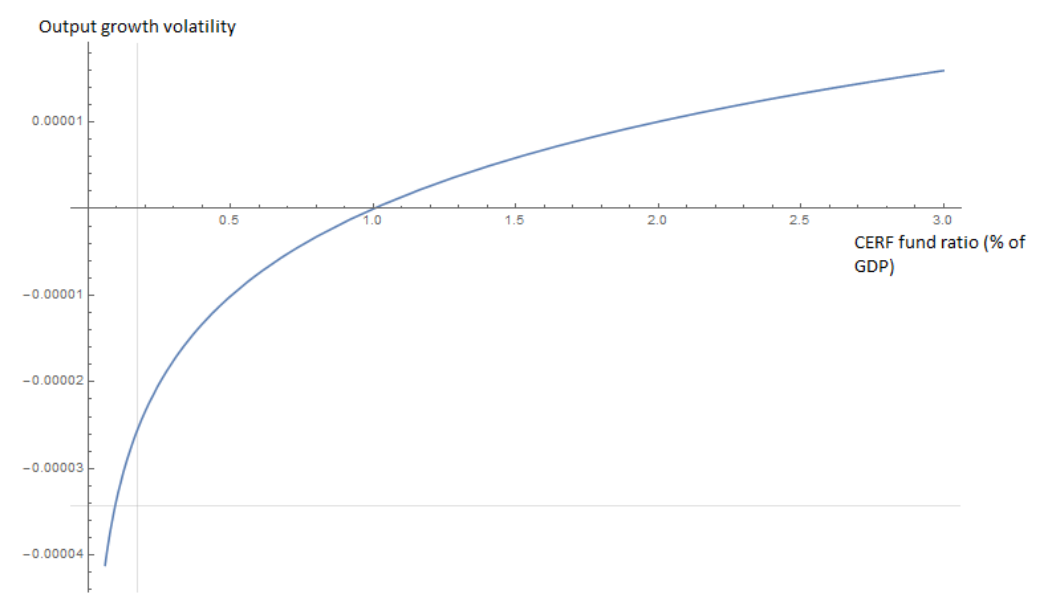

Figure 4. The specification as estimated by GMM

Figure 5 shows the expected relation between the CERF fund ratio and the output volatility according to the fixed effects method. The CERF fund ratio ranges from 2.37E-06 to 1.840113, and therefore not only the upward sloping part of the parabola is relevant. When calculating the maximum given by the estimated formula, the fixed effects method solves for $0.99 \%$ of GDP. These results suggest that for an increase in the CERF fund to decrease its effect on output growth volatility, the funding should be more than $0.99 \%$ of GDP

$100 \mid$\begin{tabular}{l|l} 
Marble \\
Research \\
Papers
\end{tabular} 


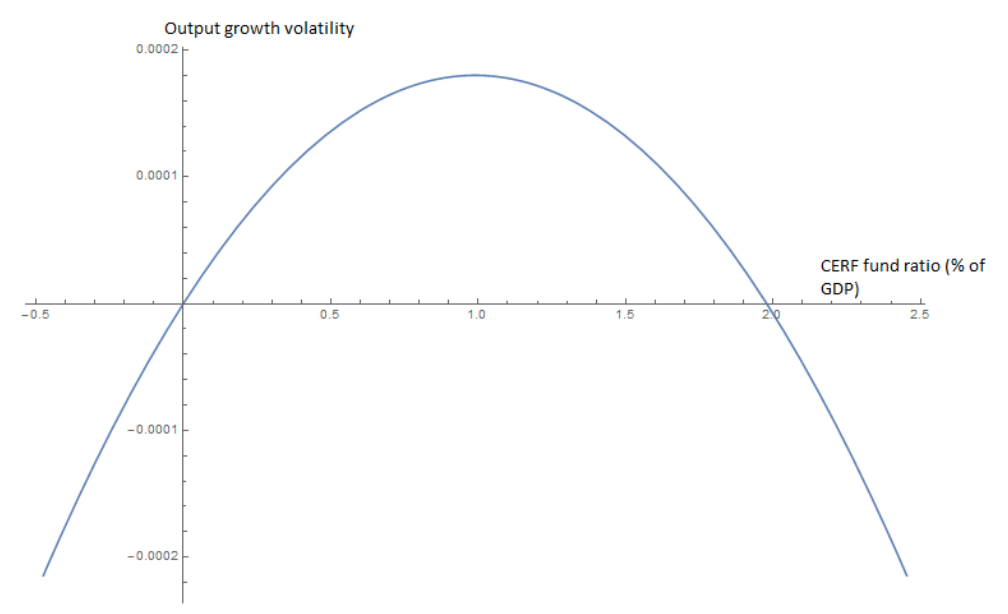

Figure 5. Parabola of the estimated results of the fixed effects method

\subsection{Model 3}

Model 3 combines the variables from the previous models. Results can be found in table 4 . The CERF funding is now measured as a dummy variable, which equals 1 when a country received CERF funding and 0 otherwise. The main interest in this model is the slope of the deaths due to natural disasters variable in combination with the allocation of CERF funding.

The simple model is first estimated without lags and in the second column lags are included. The simple model without lags again has a low P-value for the Hansen test. The coefficient of the CERF fund dummy is close to zero, which suggests no differences in the intercepts. Deaths due to a natural disaster are expected to decrease output growth volatility. When CERF funding is allocated, the expected effect of the natural disaster is close to zero $(-0.022410+0.017900)$. The model with lags estimates a positive coefficient for the natural disasters variable, and a negative one for the interaction term, both significant at a $10 \%$ level. When CERF funding is allocated, the effect is again expected to be close to zero. Also, while not significant, the natural disasters that occurred last year also are expected to have a minimal effect on the output growth volatility when CERF grants are provided.

Second, the extended model is estimated without lags and with lags. Results correspond with the simple model with lags, as combining the occurrence of a natural disaster with CERF funding leads to a coefficient of close to zero and is even slightly negative. The coefficients for the armed conflicts variables are not significant, however, including these variables improves the fit of the model. On the other hand, the number of cross-sections reduces greatly when including these.

\subsection{Robustness check}

To analyse the robustness of the obtained results, additional regressions are run. Here, instead of using the percentage of deaths due to a natural disaster, the intensity measure previously introduced is used. This implies that also those who lost their homes or got injured due to a natural disaster are taken into account. For model 1 the Hansen test P-values are again low for the simple and extended model that do not control for severity, 0.000781 and 0.004886 respectively. When adding a dummy for the severity of the disaster, the P-value is higher, 0.494218 for the simple model and 0.209977 for the extended one. Similar to previous test, the non-severe natural disasters are expected to have a small negative effect on the output growth volatility in the same year. 
Table 4 Model 3 - Natural disasters, CERF funding, and output growth volatility

\begin{tabular}{|c|c|c|c|c|}
\hline Model & 3 -Simple & 3 - Simple & 3 - Extended & 3 - Extended \\
\hline Method & GMM & GMM & GMM & GMM \\
\hline CERF fund dummy & $\begin{array}{l}1.86 \mathrm{E}-05 \\
(2.84 \mathrm{E}-05)\end{array}$ & $\begin{array}{c}0.000246 \\
(0.000176)\end{array}$ & $\begin{array}{c}0.000172 \\
(0.000105)\end{array}$ & $\begin{array}{c}0.000497 \\
(0.000285) *\end{array}$ \\
\hline Deaths natural disaster (\%) & $\begin{array}{l}-0.022410 \\
(0.012253)^{*}\end{array}$ & $\begin{array}{c}0.153632 \\
(0.092911)^{*}\end{array}$ & $\begin{array}{c}0.765261 \\
(0.415672)^{*}\end{array}$ & $\begin{array}{c}0.264455 \\
(0.226230)\end{array}$ \\
\hline $\begin{array}{l}\text { Deaths natural disaster (\%) } \\
* \text { CERF fund dummy }\end{array}$ & $\begin{array}{l}0.017900 \\
(0.012612)\end{array}$ & $\begin{array}{l}-0.157041 \\
(0.093189)^{*}\end{array}$ & $\begin{array}{l}-0.795294 \\
(0.403548)^{*}\end{array}$ & $\begin{array}{l}-0.289182 \\
(0.200125)\end{array}$ \\
\hline Deaths armed conflict (\%) & & & $\begin{array}{l}-0.110816 \\
(0.076585)\end{array}$ & $\begin{array}{l}-0.013845 \\
(0.033990)\end{array}$ \\
\hline $\begin{array}{c}\text { Deaths armed conflict (\%)* } \\
\text { CERF fund dummy }\end{array}$ & & & $\begin{array}{c}0.114383 \\
(0.077520)\end{array}$ & $\begin{array}{c}0.015139 \\
(0.030662)\end{array}$ \\
\hline $\begin{array}{l}\text { Deaths natural disaster }(\%) \\
\qquad(t-1)\end{array}$ & & $\begin{array}{c}0.017566 \\
(0.018718)\end{array}$ & & $\begin{array}{c}0.080084 \\
(0.060770)\end{array}$ \\
\hline $\begin{array}{l}\text { Deaths natural disaster }(\%) \\
(t-1) * \text { CERF fund dummy }\end{array}$ & & $\begin{array}{l}-0.018250 \\
(0.018669)\end{array}$ & & $\begin{array}{l}-0.042212 \\
(0.107479)\end{array}$ \\
\hline $\begin{array}{l}\text { Output growth volatility (t - } \\
1 \text { ) }\end{array}$ & $\begin{array}{c}0.081380 \\
(0.000567)^{* * *}\end{array}$ & $\begin{array}{c}0.082789 \\
(0.000571)^{* * *}\end{array}$ & $\begin{array}{c}0.081045 \\
(0.000717)^{* * *}\end{array}$ & $\begin{array}{c}0.083608 \\
(0.005366)^{* * *}\end{array}$ \\
\hline Cross-Sections & 71 & 59 & 41 & 36 \\
\hline Periods & 6 & 6 & 6 & 6 \\
\hline Hansen test P-value & 0.000010 & 0.792197 & 0.859338 & 0.402563 \\
\hline Number of instruments & 13 & 12 & 13 & 12 \\
\hline $\begin{array}{l}\text { Arellano-Bond test } \\
\qquad A R(1) \\
\operatorname{AR}(2)\end{array}$ & $\begin{array}{l}0.3103 \\
0.3027\end{array}$ & $\begin{array}{l}0.2075 \\
0.1564\end{array}$ & $\begin{array}{l}\text { NA } \\
\text { NA }\end{array}$ & $\begin{array}{l}\text { NA } \\
\text { NA }\end{array}$ \\
\hline
\end{tabular}

Robust-White period weights standard errors are in parentheses. Regressions are at country level and time dimension. The dependent variable is the standard deviation of GDP per capita growth. Deaths are calculated as percentage of the population. The Arellano-Bond two-step estimation method is used, GMM weighting matrix White period. * significant at 10 percent; $* *$ significant at 5 percent; *** significant at 1 percent.

The coefficient equals -0.001021 and is significant at the $5 \%$ level. Also, a severe natural disaster is expected to increase output growth volatility in the same year, with a coefficient of 0.001011 and a significance level of $5 \%$. However, when armed conflicts are added, this is not the case anymore. When measuring the natural disasters in a different way, one should apply this method too for the armed conflicts. However, precise data on the amount of people affected due to armed conflicts is hard to find.

The new estimation of model 3 does not result in useful models, since the P-values of the Hansen test are low. A few of the relevant interaction variables have a negative coefficient, which is in line with previous findings. The total effect of the natural disasters according to these estimations is not zero but slightly negative.

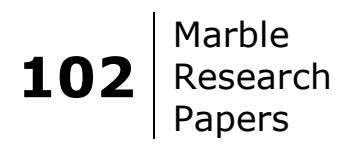




\section{Discussion}

From the data analysis, it is possible to infer conclusions which are relevant for discussing the effectiveness of CERF. Here, the null hypotheses which are stated in the methodology are evaluated.

\subsection{Model 1}

In the first model, the relationship between natural disasters and the output growth volatility is estimated. The null hypothesis is that there is a positive relation, as natural disasters affect the resources in the economy, and this is established in previous research as well. Following the results in the previous section, one can say that there is not much evidence for the deaths of natural disasters to increase output growth volatility. Non-severe natural disasters, however, have a small expected negative effect on output growth volatility. In one of the estimated models, the severe natural disasters do have an expected positive effect on output growth volatility which is significant at a $10 \%$ level, but this is not the case in the other models that are estimated. Still, the simple model controlling for severity of the natural disasters has the best fit, so there is some evidence for the null hypothesis. It is questionable whether these results are reasonable when one does not control for the funding and relief that has been received by the countries, since the ceteris paribus effect of the disaster cannot be determined. Since the dataset is based on the CERF data that is available, not all natural disasters that occurred during the time period 2006-2015 are included. This might be why the results are less strong than expected from previous research.

\subsection{Model 2}

This model evaluates the relationship between CERF funding that is allocated and output growth volatility. From the data analysis followed two possible specifications that suit the data. One is a logarithmic form with a positive slope. This implies that an increase in funding will lead to a less strong effect on the output growth volatility. However, that is not desirable, as the funding should decrease output growth volatility in order to be effective. Due to the logarithmic properties, CERF funding might only be effective up to $1 \%$ of GDP, but this depends on a possible intercept and solid conclusion cannot be drawn. One can conclude that CERF funding is to some extent effective, however, an increase in the size of the funding does not necessarily lead to less output growth volatility.

The second specification is based on the fixed effects method and suggests a parabolic shape. These results suggest that for an increase in the CERF fund to decrease its effect on output growth volatility, the funding should be more than $0.99 \%$ of GDP. Important to notice, however, is that in the database only 2 countries have received funding of more than $0.99 \%$ of GDP. As this number is small, it is debatable whether this effect still exists when the dataset would contain more of such cases. Also, similar to the GMM specification, additional variables in the formula could change this value. This specification shows that the size of the funding does matter, which is in contrast with the GMM specification.

The null hypothesis for this model was that CERF funding has a negative effect on output growth volatility. This cannot be rejected, however, it does not hold completely. From this model, it does not become clear whether the size of the CERF funding has an effect on the output growth volatility. The fixed effects method and the GMM method show contrasting results. 


\subsection{Model 3}

Once the separate effects are established, combining both the occurrence of natural disasters and the allocation of CERF funds should give an idea about the effectiveness of CERF. Even though not all models show significant results, a trend can be noticed when analysing the table with output. The coefficient of the deaths due to natural disasters (either the current year or the lag) is about the same size as the coefficient of the corresponding interaction variable. This is an important finding, as it implies that the CERF funding neutralises the effect of the natural disaster. When adding the coefficients, all reach a number that is close to zero. Thus, a natural disaster is expected to not affect the output growth volatility once CERF funding is allocated.

While this finding is important, the other results do not indicate much about the effectiveness of CERF. The interaction terms do not always have a negative sign, which is what would be expected. The simple and extended models used here, however, are very simplified and could be improved in many ways. For example, as previously done in model 1, distinguishing between severe and non-severe natural disasters could make sense. Furthermore, as seen in the estimation of model 2, the size of the CERF funding with respect to GDP is also relevant and could also be included in the model. Adding these factors complicates the model, which is why this is left to further research here.

\section{Conclusion}

Natural disasters are increasingly common and previous research shows that the economy of developing countries is more severely affected than those of developed countries. Many organisations exist that try to provide humanitarian relief after such catastrophes, which affect many human lives. The United Nations started the Central Emergency Response Fund (CERF) that allows for fast allocation of money to providers of humanitarian aid. By creating this fund before the actual occurrence of an event, the money can be allocated quickly. In 2016, CERF has been in existence for 10 years, and an evaluation of the allocated funding can provide new information in the structuring of such relief after natural disasters. Therefore, this paper answers the research question: Do the grants provided by the Central Emergency Response Fund decrease the output growth volatility caused by natural disasters?

By collecting data on CERF allocations from the years 2006-2015 and additional data on natural disasters, armed conflicts, and economic indicators, a panel dataset is constructed. Three models are estimated, which analyse the different relationships between output growth volatility, natural disasters, and CERF funding. Overall, the three models contemplate each other and results are mostly consistent. The first model showed that the effect of severe natural disasters on the output growth volatility is expected to be positive, but this result is not consistent for all estimations. Non-severe natural disasters (less than $1 \%$ of the population affected) are expected to have a positive effect. The reason that natural disasters appear to have no effect in some of the estimations can be explained when looking at the estimation of model 3, where CERF funding is included in the model. One can see here that when funding was allocated to a country after a natural disaster, the effect of the natural disaster on the economy is negligible. Furthermore, for model 2, the most suitable specifications are a logarithmic function and a linear-quadratic one. The first implies that an increase in CERF funding is only effective when it is less than $1 \%$ of GDP. The linear-quadratic specification implies a maximum. From this estimation, the expected maximum is at $0.99 \%$ of GDP. Therefore, an increase in CERF funding only decreases output growth volatility when it is beyond this point. These two specifications are in contrast with each other, and due to possible biases it is not clear which specification is more suitable.

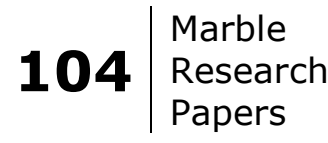


To get back to the research question, one could say that there is some evidence of CERF funding to be effective. It is effective in the sense that from these results, one could say that the funding neutralises the effect of the natural disaster. In order to confirm these results, more data is necessary. Currently, only 10 years of data are available. This lack of data can result in biases, but several econometric methods are better able to deal with that than the methods used here. The GMM-system method could be used, or the Least Dummy Squared Variable Correction method. Furthermore, different combinations of variables could be added to distinguish between different kinds of disasters and different effects over time. These are left for future research. Also, it would be interesting to see what the effect of CERF funding is on armed conflicts, instead of on natural disasters.

\section{References}

Arellano, M. and S. Bond (1991). "Some Tests of Specification for Panel Data: Monte Carlo Evidence and an Application to Employment Equations." The Review of Economic Studies 58(2): 277-297.

Baltagi, B. H. (2008). Econometric analysis of panel data. Chichester [etc.]: Wiley.

Bellemare, Marc F. and Masaki, Takaaki and Pepinsky, Thomas B., Lagged Explanatory Variables and the Estimation of Causal Effects (February 23, 2015). From:

http://dx.doi.org/10.2139/ssrn.2568724

Carter, M. R., Little, P. D., Mogues, T. and Negatu, W. (2007). "Poverty Traps and Natural Disasters in Ethiopia and Honduras." World Development 35(5): 835-856.

CERF (2016a). "CERF Funding by Country." From: www.unocha.org/cerf/cerf-worldwide/allocationscountry/2016.

CERF (2016b). "El Niño CERF-funded response in 2015-2016." From: http://reliefweb.int/sites/reliefweb.int/files/resources/CERF el-ni\%C3\%B10 20160810 2.pdf.

CERF secretariat (2015). "10 Years of Saving Lives Together: The World Helping the World." From: http://reliefweb.int/sites/reliefweb.int/files/resources/CERF\%2010\%20Report.pdf.

Channel Research (2011). "CERF 5-year evaluation synthesis report". Belgium: Ohain.

Cohen, C. and E. D. Werker (2008). "The Political Economy of ' Natural" Disasters." Journal of Conflict Resolution 52(6): 795-819.

Ebeke, C. and J.-L. Combes (2013). "Do remittances dampen the effect of natural disasters on output growth volatility in developing countries?" Applied Economics 45(16): 2241-2254.

Fomby, T., Ikeda, Y. and Loayza, N.V. (2013). "The Growth Aftermath of Natural Disasters." Journal of Applied Econometrics 28(3): 412-434.

Hall, A. R. (2005). Generalized method of moments. Oxford [etc.]:, Oxford University Press.

Hansen, L. P. (1982). "Large Sample Properties of Generalized Method of Moments Estimators." Econometrica 50(4): 1029-1054.

Hujer, R., Rodrigues, P. J. M. and Zeiss, C. (2005). Serial correlation in dynamic panel data models with weakly exogenous regressor and fixed effects. Working paper. Frankfurt am Main, Univ.: Online-Resource.

Kuropka, A. and A. H. Jankowiak (2016). "The Impact of Natural Disasters on Economy and Production Networks in ASEAN." WPŁYW KATASTROF NATURALNYCH NA GOSPODARKE I SIECI PRODUKCYJNE W ASEAN.(447): 111-122.

Melander, E. and R. Sundberg (2013). "Introducing the UCDP Georeferenced Event Dataset." Journal 
Of Peace Research 50(4): 523-532.

Mileva, E. (2007). "Using Arellano Bond Dynamic Panel GMM Estimators in Stata."From https://www.researchgate.net/file.PostFileLoader.html?id=575fcb0a217e200cb31d2f1 f\&assetKey=AS\%3A372807700631552\%401465895690276.

Porfiriev, B. N. (2016). "The economics of natural disasters." Herald of the Russian Academy of Sciences 86(1): 1-11.

Raddatz, C. (2009) The Wrath Of God: Macroeconomic Costs Of Natural Disasters. The Wrath Of God: Macroeconomic Costs Of Natural Disasters. DOI: doi:10.1596/1813-9450-5039

Samphantharak, K. (2014). "Natural disasters and the economy: some recent experiences from Southeast Asia." Asian-Pacific Economic Literature 28(2): 33-51.

Spiegel, P. B., Le, P., Salama, P. and Ververs, M. (2007). "Occurrence and overlap of natural disasters, complex emergencies and epidemics during the past decade (1995-2004)." Conflict and Health 1: 2-2.

Strömberg, D. (2007). "Natural Disasters, Economic Development, and Humanitarian Aid." Journal of Economic Perspectives 21(3): 199-222.

Wooldridge, J. M. (2013). Introductory econometrics: a modern approach. Australia, etc.: SouthWestern/Cengage Learning.

World Health Organization (2010). "United Nations Central Emergency Response Fund (CERF) Grants. Basic Facts and Information." From:

http://www2.wpro.who.int/internet/files/eha/toolkit/web/Technical\%20References/Ce ntral\%20Emergency\%20Response\%20Fund/CERF\%20Basic\%20Facts\%20and\%20In formation.pdf. 